\title{
Identification of a novel nonsense mutation in SH2D1A in a patient with X-linked lymphoproliferative syndrome type $1:$ a case report
}

\author{
Xiaodong Lyu', Zhen Guo ${ }^{1}$, Yangwei Li ${ }^{1}$, Ruihua Fan ${ }^{1}$ and Yongping Song ${ }^{2^{*}}$ (])
}

\begin{abstract}
Background: X-linked lymphoproliferative syndrome type 1 (XLP1) is an X-linked recessive genetic disorder with a strong resemblance to hemophagocytic lymphohistiocytosis $(H L H)$. Causative mutations for XLP1 have been identified in SH2D1A, located on chromosome Xq25.

Case presentation: We report a case of an 18-month-old male with a novel nonsense mutation in SH2D1A. The patient presented the typical phenotype of $\mathrm{HLH}$, including splenomegaly and hemophagocytosis in the bone marrow. Thus, he was initially diagnosed with HLH based on HLH-2004 guidelines. High-throughput amplicon sequencing was performed to detect mutations in the most commonly reported causative genes of HLH, i.e., PRFT, UNC13D, STX11, STXBP2, SH2D1A, and XIAP. A likely pathogenic nonsense mutation was detected in SH2D1A (NM_ 002351.4:C.300T>A). The mutation was inherited from the patient's mother, and an X-linked recessive mode of inheritance was confirmed by a two-generation pedigree analysis based on Sanger sequencing results.

Conclusions: The nonsense mutation in SH2D1A (NM_002351.4:c.300T>A) was reported for the first time in a case of XLP1 and was considered to be likely pathogenic based on the truncation of the mRNA sequence. This finding expands the spectrum of known XLP-related mutations in Chinese patients and indicates the utility of amplicon sequencing for XLP and HLH diagnosis.
\end{abstract}

Keywords: XLP1, SH2D1A, Nonsense mutation, Amplicon sequencing

\section{Background}

X-linked lymphoproliferative syndrome type 1 (XLP1; OMIM 308240), also known as Duncan disease, was initially reported in the 1970s [1]. It is an X-linked recessive genetic disorder caused by mutations in the SH2D1A gene, which is located on chromosome Xq25. SH2D1A encodes a src-homology $2(\mathrm{SH} 2)$ domain in a signal-transducing protein, i.e., SLAM-associated protein (SAP), which is important for signaling events activating $\mathrm{T}$ and NK cells [2]. The phenotype of XLP1 has a strong resemblance to that of hemophagocytic lymphohistiocytosis (HLH) [3], including fever, splenomegaly, and

\footnotetext{
* Correspondence: ypsong2017@163.com

2Department of Hematology, the Affiliated Cancer Hospital of Zhengzhou

University, Henan Cancer Hospital, Zhengzhou 450000, Henan, China

Full list of author information is available at the end of the article
}

cytopenia. XLP1 is often triggered by Epstein-Barr virus infection [4]. The incidence of XLP in the United States was estimated to be approximately 1 in 1 million males [5], but the incidence and mutation spectrum of XLP in China remain unknown owing to limited epidemiological data.

We report an 18-month-old male patient who was initially diagnosed with HLH based on clinical examination. However, a diagnosis of XLP1 was confirmed based on amplicon sequencing results, and a novel pathogenic nonsense mutation (c.300T>A) in SH2D1A was identified. Furthermore, a two-generation pedigree analysis was performed to confirm the mode of inheritance of the mutation in the patient.

(c) The Author(s). 2018 Open Access This article is distributed under the terms of the Creative Commons Attribution 4.0 International License (http://creativecommons.org/licenses/by/4.0/), which permits unrestricted use, distribution, and reproduction in any medium, provided you give appropriate credit to the original author(s) and the source, provide a link to the Creative Commons license, and indicate if changes were made. The Creative Commons Public Domain Dedication waiver (http://creativecommons.org/publicdomain/zero/1.0/) applies to the data made available in this article, unless otherwise stated. 


\section{Case presentation}

The study was approved by the institutional ethics committee of the Affiliated Cancer Hospital of Zhengzhou University. The CARE guidelines were followed in reporting this case. Written informed consent was obtained from the patient's parents before collecting blood samples.

The patient was an 18-month-old male of Han Chinese ethnicity (with family from Henan province, China) who had intermittent fever for 2 weeks and was admitted to the Affiliated Cancer Hospital of Zhengzhou University. His temperature was $39.0{ }^{\circ} \mathrm{C}$, and hepatomegaly was observed during an ultrasound examination. Blood analysis revealed elevated $\mathrm{C}$-reactive protein levels, mild pancytopenia, low NK cell activity (4.65\%), and low plasma albumin levels $(18.8 \mathrm{~g} / \mathrm{L})$. Hemophagocytosis with no evidence of malignancy was observed during bone marrow examination (Fig. 1). The laboratory test results suggested the typical phenotype of HLH, based on HLH-2004 guidelines [6].

Genomic DNA was extracted from peripheral blood mononuclear cells (PBMCs) using the QIAamp Blood Kit (Qiagen, Hilden, Germany) according to the manufacturer's protocol. Multiple PCR primers were designed using the Ion AmpliSeq ${ }^{\mathrm{Tm}}$ Designer (https://www.ampliseq.com) to amplify the full-length exons of the 6 most common causative genes of HLH (PRF1, UNC13D, STX11, STXBP2, $S H 2 D 1 A$, and $X I A P)$. PCR products were processed and sequenced using the S5XL genetic analyzer (Applied Biosystems $^{\circ}$, Life Technologies, Grand Island, NY, USA), and mutations were identified using VariantCaller V1.0.

Eleven mutations were detected, including 8 heterozygous and 3 homozygous mutations (Table 1). All mutations were identified as polymorphisms based on sequences in current databases and clinical reports, except for the mutation NM_002351.4:c.300T>A (p. Tyr100X), which has not been reported to date. This

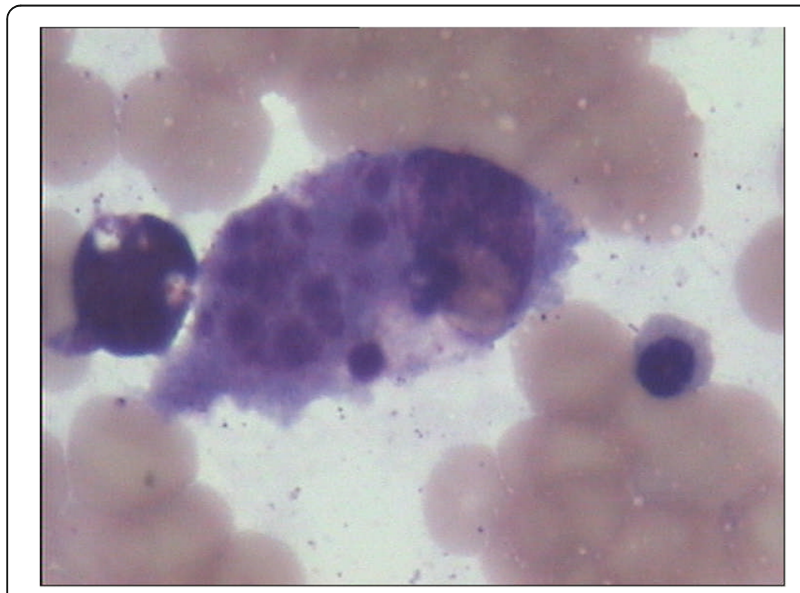

Fig. 1 Bone marrow examination. Phagocytosis was clearly observed in the bone marrow, but no evidence of malignancy was observed mutation in exon 3 of $S H 2 D 1 A$, located on chromosome Xq25 (NC_000023.10:g.123504124, GRCh37), converts the codon for tyrosine to a stop codon (TAT>TAA). Several previously reported mutations in $S H 2 D 1 A$ are involved in the pathogenesis of XLP1 and could lead to a similar phenotype to that of HLH $[7,8]$.

To investigate the impact of this mutation on mRNA transcription, we performed RT-PCR with total RNA extracted from the blood sample obtained from the patient. Then, cDNA was synthesized using SuperScript IV Reverse Transcriptase (Thermo Fisher Scientific, Waltham, MA, USA) according to the manufacturer's protocol. PCR primers were designed using primer-BLAST (https://www.ncbi.nlm.nih.gov/tools/primer-blast) (Fig. 2a and Additional file 1: Table S1) to confirm the truncated cDNA sequence caused by the nonsense mutation. A full-length cDNA clone of the SH2D1A gene (SC118690; OriGene Technologies, Beijing, China) was included as control sample. For the full-length cDNA clone, PCR products were obtained using both pairs of primers, resulting in DNA fragments of 409 and $324 \mathrm{bp}$, respectively (Fig. 2b, lane 1 and lane 2). For the truncated cDNA from the patient, amplification was only possible using the second pair of primers due to the mutation (Fig. 2b, lane 3 and lane 4). Gel electrophoresis showed that the mRNA sequence of the SH2D1A gene in the patient was truncated, suggesting a loss or partial loss of protein function.

To confirm the mutation source, we performed a twogeneration pedigree analysis using Sanger sequencing. The Sanger sequencing results were identical to those obtained by amplicon sequencing. The nonsense mutation in SH2D1A was carried by the patient's mother, who showed a typical heterozygous profile (Fig. 3). This result confirmed an X-linked recessive inheritance pattern.

\section{Discussion and conclusions}

We present the case of an 18-month-old male patient, who presented typical features of HLH in clinical examination, including hepatomegaly, low platelet counts, decreased NK cell activity, and hemophagocytosis, but was finally diagnosed with XLP1 by amplicon sequencing. A likely pathogenic nonsense mutation, NM_002351.4:c. $300 \mathrm{~T}>\mathrm{A}$, was identified by amplicon sequencing and confirmed by Sanger sequencing. X-linked recessive inheritance was identified based on a two-generation pedigree analysis. Gel electrophoresis of the RT-PCR product showed a truncated mRNA sequence of the SH2D1A gene in the patient.

The SH2D1A gene encodes the SH2 domain in SLAM-associated protein (SAP). To our knowledge, this domain consists of a phosphotyrosine binding pocket (pTyr-binding pocket), hydrophobic binding pocket, and a $\beta G$ strand, which is highly important for SLAM binding 
Table 1 Identified mutations in the patient with XLP1

\begin{tabular}{|c|c|c|c|c|c|c|}
\hline Gene-exon & Position & Type & Zygosity & Frequency of variant (\%) & ID in dbSNP & ${ }^{a}$ Allele frequencies in 1000 Genomes \\
\hline PRF1-Exon3 & c. $900 C>T$ & Synonymous & Heterozygous & 50 & rs885822 & 0.6959 \\
\hline PRF1-Exon3 & c. $822 C>T$ & Synonymous & Heterozygous & 49 & rs885821 & 0.1126 \\
\hline UNC13D-Exon32 & c.3198A $>\mathrm{G}$ & Synonymous & Heterozygous & 54 & rs7210574 & 0.5262 \\
\hline UNC13D-Exon27 & c. $2599 A>G$ & Missense & Heterozygous & 46 & rs1135688 & 0.4994 \\
\hline UNC13D-Exon21 & c. $1992+5 G>A$ & Intron mutation & Heterozygous & 55 & rs17581728 & 0.1575 \\
\hline UNC13D-Exon11 & $\mathrm{c} .888 \mathrm{G}>\mathrm{C}$ & Synonymous & Heterozygous & 51 & rs7223416 & 0.5098 \\
\hline STXBP2-Exon10 & $\mathrm{c} .849 \mathrm{G}>\mathrm{A}$ & Synonymous & Heterozygous & 47 & rs34450592 & 0.0124 \\
\hline STXBP2-Exon18 & C. $1576 A>G$ & Missense & Homozygous & 100 & rs6791 & 0.7061 \\
\hline STXBP2-Exon18 & C. $1663 A>G$ & Missense & Heterozygous & 65 & rs61736586 & 0.0122 \\
\hline XIAP-Exon7 & c. ${ }^{\mathrm{a}} 12 \mathrm{~A}>\mathrm{G}$ & Non-coding region & Hemizygote & 100 & rs 28382740 & 0.2673 \\
\hline SH2D1A-Exon3 & c.300T>A & Nonsense & Hemizygote & 100 & not applicable & not applicable \\
\hline
\end{tabular}

a Allele frequencies were collected from The 1000 Genome Project: phase 3 (https://www.ncbi.nlm.nih.gov/variation/tools/1000genomes)

[9]. Hence, mutations within the boundaries of the domain could directly implicate the $\mathrm{SH} 2$ domain in the pathogenesis of XLP [10]. However, the nonsense mutation we detected in this study is located around the $\beta G$ strand (p. Tyr100X) and results in a loss of function of SAP.

XLP1 is a primary immunodeficiency caused by mutations in SH2D1A; another subtype of XLP is X-linked lymphoproliferative syndrome, type 2 (XLP2), for which the causative gene is XIAP, located on chromosome
Xq25. Both of these two subtypes could be triggered by virus infection and present a strong resemblance to HLH. Detailed descriptions of XLP1 and XLP2 have been provided, including their clinical features, molecular genetics, and pathophysiology [11, 12]. However, the mutation spectrum and epidemiological features of this disease in China are unclear. Our results expand the spectrum of pathogenic mutations in $S H 2 D 1 A$, and may contribute to further epidemiological surveys of XLP.

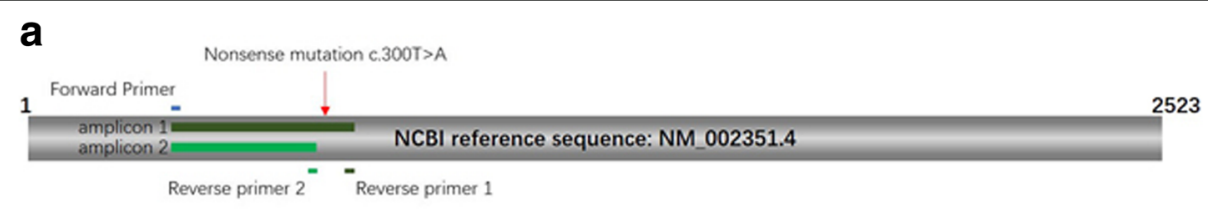

b

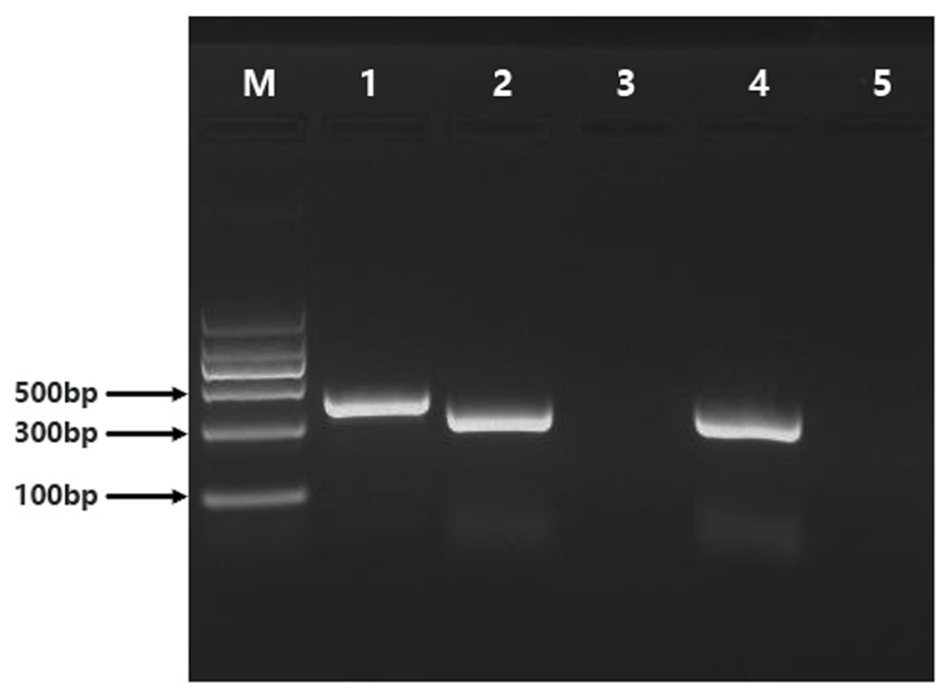

Fig. 2 RT-PCR analysis of the SH2D1A gene. a Primer pairs and amplicons in the CDNA sequence of the SH2D1A gene. $\mathbf{b}$ Gel electrophoresis of RT-PCR products for the SH2D1A gene. M: DNA marker; lane 1: amplicon 1 of the control sample; lane 2: amplicon 2 of the control sample; lane 3: amplicon 1 of the patient's sample; lane 4: amplicon 2 of the patient's sample; lane 5: negative control 

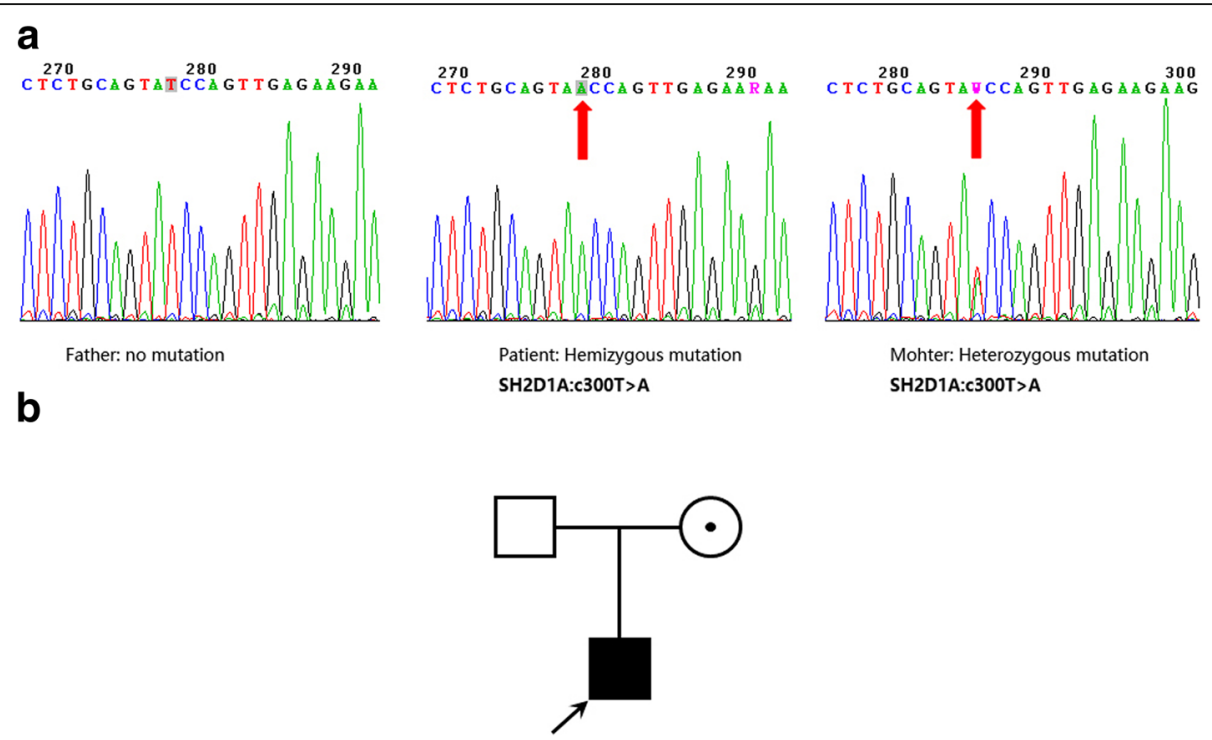

Fig. 3 Two-generation pedigree analysis. a Sanger sequencing results of the amplified fragment in SH2D1A exon 3. The red arrows indicate the position of the identified mutation. $\mathbf{b}$ Family pedigree of the SH2D1A mutation found in the patient. The white square represents the father who is normal in this case, the white circle with a dot represents the mother who is a carrier of the X-linked recessive genetic disorder, the black square with an arrow represents the patient who is the proband

Differential diagnosis of HLH is essential to ensure appropriate treatment. The phenotypes of XLP1 and HLH are highly similar, necessitating a rapid and accurate approach for differential diagnosis. Since the genetic factors of XLP and most subtypes of HLH are clear, amplicon sequencing could be an efficient and cost-saving method. In this case, all mutations in the target region were sequenced and analyzed in $24 \mathrm{~h}$, with a cost of less than 100 dollars. Furthermore, our findings demonstrate that this technology can be used for the identification of novel mutations, in addition to known ones; thus, they have has implications for the improvement of genetic counseling and diagnosis for inherited diseases.

In conclusion, we used amplicon sequencing to identify a novel nonsense mutation in $S H 2 D 1 A$ in a male patient with XLP1; the mutation was inherited from his mother, according to the X-linked recessive mode of inheritance. The RT-PCR results showed a truncated mRNA sequence in the patient due to the mutation, indicating a loss or partial loss of protein function. This finding also extends the spectrum of known XLP-related mutations in Chinese patients, and demonstrates the utility of amplicon sequencing for the identification of novel mutations and for differential diagnosis.

\section{Additional file}

Additional file 1: Table S1. Information of primers for RT-PCR of SH2D1A gene. (DOCX $16 \mathrm{~kb})$

\section{Abbreviations}

HLH: hemophagocytic lymphohistiocytosis; XLP1: X-linked

lymphoproliferative syndrome, type 1

\section{Acknowledgements}

The authors appreciate the participation of the patient and his family in this clinical study. This work was supported by the Affiliated Cancer Hospital of Zhengzhou University. We would like to thank Editage (www.editage.cn) for English language editing.

\section{Funding}

This work was supported by the National Natural Science Foundation of China (NSFC) [ID: 81470287] and the Henan Medical Research Foundation of Henan Health Department [ID: 201602286].

\section{Availability of data and materials}

The sequence data have been deposited in the NCBI Short Read Archive under accession number SRR6282621, the data is available for downloading with the following link: https://trace.ncbi.nlm.nih.gov/Traces/sra/ ?run=SRR6282621.

\section{Authors' contributions}

$\mathrm{XL}$ and ZG performed the experiments. YL and RF performed the clinical examination and bone marrow examination. $X \mathrm{~L}$ and $\mathrm{YS}$ analyzed data and wrote the manuscript. YS designed the study and edited the manuscript. All authors read and approved the final manuscript.

\section{Ethics approval and consent to participate}

This study was approved by the institutional ethics committee of the Affiliated Cancer Hospital of Zhengzhou University. Written informed consent was obtained from the patient's parents before the collection of blood samples.

\section{Consent for publication}

Written informed consent was obtained from the patient's parents for the publication of this case report and any accompanying data and images. A copy of the written consent is available for review by the journal editor. All authors have approved the publication of this manuscript.

\section{Competing interests}

The authors declare that they have no competing interests. 


\section{Publisher's Note}

Springer Nature remains neutral with regard to jurisdictional claims in published maps and institutional affiliations.

\section{Author details}

${ }^{1}$ Central Laboratory, the Affiliated Cancer Hospital of Zhengzhou University, Henan Cancer Hospital, Zhengzhou 450000, Henan, China. ${ }^{2}$ Department of Hematology, the Affiliated Cancer Hospital of Zhengzhou University, Henan Cancer Hospital, Zhengzhou 450000, Henan, China.

Received: 27 November 2017 Accepted: 4 April 2018

Published online: 12 April 2018

\section{References}

1. Purtilo DT, Cassel CK, Yang JPS. Letter: fatal infectious mononucleosis in familial lymphohistiocytosis. N Engl J Med. 1974;291(14):736.

2. Morra M, Simarrogrande M, Martin M, Chen ASI, Lanyi A, Silander OK, Calpe S, Davis JR, Pawson T, Eck MJ. Characterization of SH2D1A missense mutations identified in X-linked lymphoproliferative disease patients. J Biol Chem. 2001;276(39):36809-16.

3. Arico M, Imashuku S, Clementi R, Hibi S, Teramura T, Danesino C, Haber DA, Nichols KE. Hemophagocytic lymphohistiocytosis due to germline mutations in SH2D1A, the X-linked lymphoproliferative disease gene. Blood. 2001:97(4):1131-3.

4. Booth C, Gilmour K, Veys P, Gennery AR, Slatter M, Chapel H, Heath PT, Steward CG, Smith OP, Omeara A. X-linked lymphoproliferative disease due to SAP/SH2D1A deficiency: a multicenter study on the manifestations, management and outcome of the disease. Blood. 2011;117(1):53-62.

5. Sandlund JT, Shurtleff SA, Onciu M, Horwitz EM, Leung W, Howard V, Rencher R, Conley ME. Frequent mutations in SH2D1A (XLP) in males presenting with high-grade mature B-cell neoplasms. Pediatr Blood Cancer. 2013;60(9):E85-7.

6. Henter Jl, Horne A, Arico M, Egeler RM, Filipovich AH, Imashuku S, Ladisch S, McClain K, Webb D, Winiarski J, et al. HLH-2004: diagnostic and therapeutic guidelines for hemophagocytic lymphohistiocytosis. Pediatr Blood Cancer. 2007:48(2):124-31.

7. Hare NJ, Ma CS, Alvaro F, Nichols KE, Tangye SG. Missense mutations in SH2D1A identified in patients with X-linked lymphoproliferative disease differentially affect the expression and function of SAP. Int Immunol. 2006; 18(7):1055-65.

8. Sumegi J, Huang D, Lanyi A, Davis JD, Seemayer TA, Maeda A, Klein G, Seri $M$, Wakiguchi H, Purtilo DT. Correlation of mutations of the SH2D1A gene and Epstein-Barr virus infection with clinical phenotype and outcome in Xlinked lymphoproliferative disease. Blood. 2000;96(9):3118-25.

9. Poy F, Yaffe MB, Sayos J, Saxena K, Morra M, Sumegi J, Cantley LC, Terhorst C, Eck MJ. Crystal structures of the XLP protein SAP reveal a class of SH2 domains with extended, phosphotyrosine-independent sequence recognition. Mol Cell. 1999:4(4):555-61.

10. Hwang PM, Li C, Morra M, Lillywhite J, Muhandiram DR, Gertler F, Terhorst C, Kay LE, Pawson T, Forman-Kay JD. A 'three-pronged'binding mechanism for the SAP/SH2D1A SH2 domain: structural basis and relevance to the XLP syndrome. EMBO J. 2002;21(3):314-23.

11. Latour S, Aguilar C. XIAP deficiency syndrome in humans. Semin Cell Dev Biol. 2015;39:115-23. Academic Press

12. Booth C, Gilmour KC, Veys P, Gennery AR, Slatter MA, Chapel H, Heath PT, Steward CG, Smith O, O'Meara A. X-linked lymphoproliferative disease due to SAP/SH2D1A deficiency: a multicenter study on the manifestations, management, and outcome of the disease. Blood. 2010; https://doi.org/10 1182/blood-2010-06-284935.

\section{Ready to submit your research? Choose BMC and benefit from:}

- fast, convenient online submission

- thorough peer review by experienced researchers in your field

- rapid publication on acceptance

- support for research data, including large and complex data types

- gold Open Access which fosters wider collaboration and increased citations

- maximum visibility for your research: over $100 \mathrm{M}$ website views per year

At BMC, research is always in progress.

Learn more biomedcentral.com/submissions 